\title{
Prognostic potential of automated Ki67 evaluation in breast cancer: different hot spot definitions versus true global score
}

\author{
Stephanie Robertson ${ }^{1,2}$ (B) Balazs Acs ${ }^{1,2} \cdot$ Michael Lippert $^{3} \cdot$ Johan Hartman ${ }^{1,2}$
}

Received: 11 April 2020 / Accepted: 13 June 2020 / Published online: 22 June 2020

(C) The Author(s) 2020

\begin{abstract}
Purpose The proliferation-associated biomarker Ki67 has potential utility in breast cancer, including aiding decisions based on prognosis, but has unacceptable inter- and intralaboratory variability. The aim of this study was to compare the prognostic potential for Ki67 hot spot scoring and global scoring using different digital image analysis (DIA) platforms.

Methods An ER+/HER2- breast cancer cohort $(n=139)$ with whole slide images of sequential sections stained for hematoxylin-eosin, pancytokeratin and Ki67, was analyzed using two DIA platforms. For hot spot analysis virtual dual staining was applied, aligning pancytokeratin and Ki67 images and 22 hot spot algorithms with different features were designed. For global Ki67 scoring an automated QuPath algorithm was applied on Ki67-stained whole slide images. Clinicopathological data included overall survival (OS) and recurrence-free survival (RFS) along with PAM50 molecular subtypes.

Results We show significant variations in Ki67 hot spot scoring depending on number of included tumor cells, hot spot size, shape and location. The higher the number of scored tumor cells, the higher the reproducibility of Ki67 proliferation values. Hot spot scoring had greater prognostic potential for RFS in high versus low Ki67 subgroups (hazard ratio (HR) 6.88, CI 2.07-22.87, $p=0.002$ ), compared to global scoring (HR 3.13, CI 1.41-6.96, $p=0.005$ ). Regarding OS, global scoring (HR 7.46, CI 2.46-22.58, $p<0.001$ ) was slightly better than hot spot scoring (HR 6.93, CI 1.61-29.91, $p=0.009$ ). In adjusted multivariate analysis, only global scoring was an independent prognostic marker for both RFS and OS. In addition, global Ki67-based surrogate subtypes reached higher concordance with PAM50 molecular subtype for luminal A and B tumors ( $66.3 \%$ concordance rate, $\kappa=0.345)$, than using hot spot scoring $(55.8 \%$ concordance rate, $\kappa=0.250$ ).
\end{abstract}

Conclusions We conclude that the automated global Ki67 scoring is feasible and shows clinical validity, which, however, needs to be confirmed in a larger cohort before clinical implementation.

Keywords Breast cancer $\cdot$ Ki67 $\cdot$ Digital pathology $\cdot$ Digital image analysis $\cdot$ Immunohistochemistry

\section{Introduction}

Electronic supplementary material The online version of this article (https://doi.org/10.1007/s10549-020-05752-w) contains supplementary material, which is available to authorized users.

Stephanie Robertson

stephanie.robertson@ki.se

1 Department of Oncology and Pathology, CCK, Karolinska Institutet, R8:04, 17176 Stockholm, Sweden

2 Department of Clinical Pathology and Cytology, Karolinska University Laboratory, Stockholm, Sweden

3 Visiopharm A/S, Hoersholm, Denmark
Tumor proliferation is one of the hallmarks of cancer. The proliferation-associated nuclear protein Ki67 is expressed in all phases of the cell cycles except for $\mathrm{G}_{0}$ [1]. In many countries, immunohistochemistry-based assessment of Ki67 is part of the routine biomarker evaluation of breast cancers along with estrogen receptor (ER), progesterone receptor (PR) and human epidermal growth factor receptor 2 (HER2). Ki67 has been used for over two decades as a prognostic biomarker in early breast cancer [2-4], and tumor proliferation may be used to guide clinical decisions concerning chemotherapy [5].

Breast cancer is a heterogeneous disease and can be classified into the intrinsic molecular subtypes: luminal A, luminal B, HER2-enriched and basal-like [6]. These 
intrinsic subtypes as first described by Sorlie and Perou hold both predictive and prognostic information [7,8]. The majority of luminal tumors are hormone receptor (HR)-positive and account for $70 \%$ of all breast cancer cases. Luminal A tumors have low proliferation and good prognosis with high sensitivity to endocrine therapy [9, 10], whereas luminal B tumors are highly proliferative and are less sensitive to endocrine therapy with a poorer prognosis [11, 12]. The HER2-enriched subtypes are aggressive tumors with poor prognosis; however, they are effectively targeted by anti-HER 2 therapy with improved prognosis [13]. The majority of the basal-like subtype have a triple-negative phenotype. However, molecular profiling of breast cancer is expensive and not routinely available in breast pathology, and instead, immunohistochemical assessment of ER, PR, HER2 and Ki67 is used for surrogate subtype classification of the intrinsic molecular subtypes [5, 9, 14, 15]. Among HR+/HER2- tumors, Ki67 is important to distinguish luminal A-like and luminal B-like tumors and thereby the need for added chemotherapy $[16,17]$.

Intra- and interlaboratory variability of Ki67 assessment is known to hinder its reproducibility $[18,19]$. International recommendations for Ki67 are controversial, due to lack of standardization, and as a consequence, laboratory-specific cut-off values have been recommended [5]. Despite efforts over the past years to establish robust recommendations, there is no international consensus regarding Ki67 cut-offs and the most appropriate method for Ki67 scoring [15, 20, 21]. International guidelines state that 1000 tumor cells should be counted, with an absolute minimum of 500 cells $[5,20]$. In contrast, the national Swedish guidelines have concluded that 200 tumor cells should be counted in a hot spot region [22].

Digital image analysis (DIA) has been suggested as a method to improve reproducibility of Ki67, which has been demonstrated in several studies [23-25]. It was previously shown that DIA of Ki67 outperforms manual assessment and specifically the ability of DIA of Ki67 in hot spots to distinguish between luminal A- and B-like disease [26, 27]. The International Ki67 in Breast Cancer Working Group (IKWG) suggests automated average Ki67 scoring methods based on reproducibility, but states that the methods require further standardization and clinical validation [24].

A precise definition of a hot spot for Ki67 scoring is lacking in international guidelines, as well as recommendation for which assessment method to use $[5,15,28]$. The aim of this study was to compare the prognostic potential for Ki67 hot spot scoring and global scoring using different DIA platforms among ER+/HER2- breast cancers.

\section{Materials and methods}

\section{Breast cancer study cohort}

This retrospective study comprised a previously published cohort of patients diagnosed with invasive breast carcinoma at the Karolinska University Hospital, Sweden during 2002-2009 and the Stockholm South General Hospital, Sweden during 2012 [26, 27, 29, 30]. From this cohort, a total of 217 tumors were available for DIA (Supplementary Fig. S1). Clinicopathological data including up to 15 years of follow-up outcome data was retrieved from the pathology laboratory information system and the medical record system. Recurrence-free survival (RFS) was defined as no breast cancer recurrence at end of follow-up. Overall survival (OS) was defined as no death from any cause at end of follow-up. The "Reporting recommendations for tumor marker prognostic studies (REMARK)" were followed [31].

\section{Immunohistochemistry}

Tissue serial sections were retrieved from formalin-fixed paraffin-embedded tumors at the accredited clinical laboratory of the Department of Pathology, Karolinska University Laboratory, Sweden. The sections were serially stained with a rabbit monoclonal anti-Ki67 antibody (clone 30-9) by Ventana and a mouse monoclonal anti-CKMNF116 antibody by Agilent Dako, according to manufacturer's protocol, as described previously [27].

\section{Ki67 cut-offs and surrogate subtype classification}

For assessment of Ki67 scoring methods and prognostic potential only ER+/HER2- luminal A-like and B-like tumors were included in the analysis. We adopted the St Gallen 2013 consensus recommendations for immunohistochemistry (IHC)-based surrogate subtype classification with a $<20 \%$ cut-off for low Ki67 [5]. Luminal A-like was defined as ER+/HER2- with PR $\geq 20 \%$ and low Ki67. Consequently, luminal B-like (non-HER2) was defined as ER+/HER2- with PR $<20 \%$ or high Ki67, as previously described by Robertson et al. [32]. HER2+ tumors were excluded since therapy choices for this tumor group is not primarily determined by proliferation index.

\section{PAM50 gene expression-based subtypes}

For comparisons with molecular intrinsic subtypes available data on PAM50 gene expression-based subtypes were used. RNA extraction for gene expression analysis had been 
performed on snap-frozen tumor tissue as described previously $[29,30]$. Based on the PAM50 algorithm, tumors had been assigned a molecular subtype (luminal A, luminal B, HER2-enriched or basal-like). No new gene expression analysis was performed for this study.

\section{Digital image analysis platforms}

Digitalized whole slide images of tumor sections of Ki67 and CKMNF116 had previously been scanned with the NanoZoomer 2.0-HT (Hamamatsu Photonics K.K., Hamamatsu, Japan) platform at 20x, with a pixel size of $0.4537 \times 0.4537 \mu \mathrm{m}$. Automated DIA algorithms for hot spot scoring were designed in the Visiopharm Integrator Software (VIS) (Visiopharm A/S, Hoersholm, Denmark). For global Ki67 scoring the open source software QuPath was used [33].

\section{Ki67 hot spot analysis}

The Ki67-stained images were aligned with the CKMNF116-stained images in VIS using the Tissuealign module (Fig. 1). The tumor region detection operates by a VirtualDoubleStaining ${ }^{\mathrm{TM}}$ method, and accurately detects tumor cells (including non-invasive tumor components) and excludes non-epithelial cells e. g. proliferating lymphocytes and background tissue. Automated detection of tumor regions of interest (ROI) was performed using the pancytokeratin (PCK) VirtualDoubleStaining ${ }^{\mathrm{TM}}$ APP (ID:
10165) and Ki67 index (\%) was estimated using the CEIVD approved Ki67 APP (ID: 90004) identifying positive and negative tumor cell nuclei within the tumor regions. The PCK and Ki67 APP have previously been calibrated to the staining protocol and platform used at our department [27]. A hot spot was identified by applying the CE-IVD approved Hot Spot APP (ID: 20114, ver. 0.2) which is based on a heatmap of the density of Ki67-positive nuclei. Ki67 quantification (\%) within the hot spot was performed by counting the number of positive nuclei divided by the total number of nuclei (Fig. 1). All images were reviewed by a pathologist and larger areas of non-invasive tumor within the ROIs were removed and all hot spots were confirmed to be in invasive ROIs.

\section{Hot spot parameters}

We investigated different configurable parameters of the Hot Spot APP in VIS. The four identified parameters were the drawing radius, shape, positive cells or positive ratio, and total number of cells (Table 1). The hot spot was based on a heatmap using either the number of Ki67-positive cells or the ratio of positive cells in the tumor. The heatmap was generated by first creating an empty image at a much lower resolution than the virtual slide, with 0's in all pixels. Then for each positive object in the image we added 1 to the heatmap image in a predefined drawing radius. The higher the radius, the more blurred heatmap, and the more round and cohesive the hot spot would be. We applied either a $20 \times$ or a
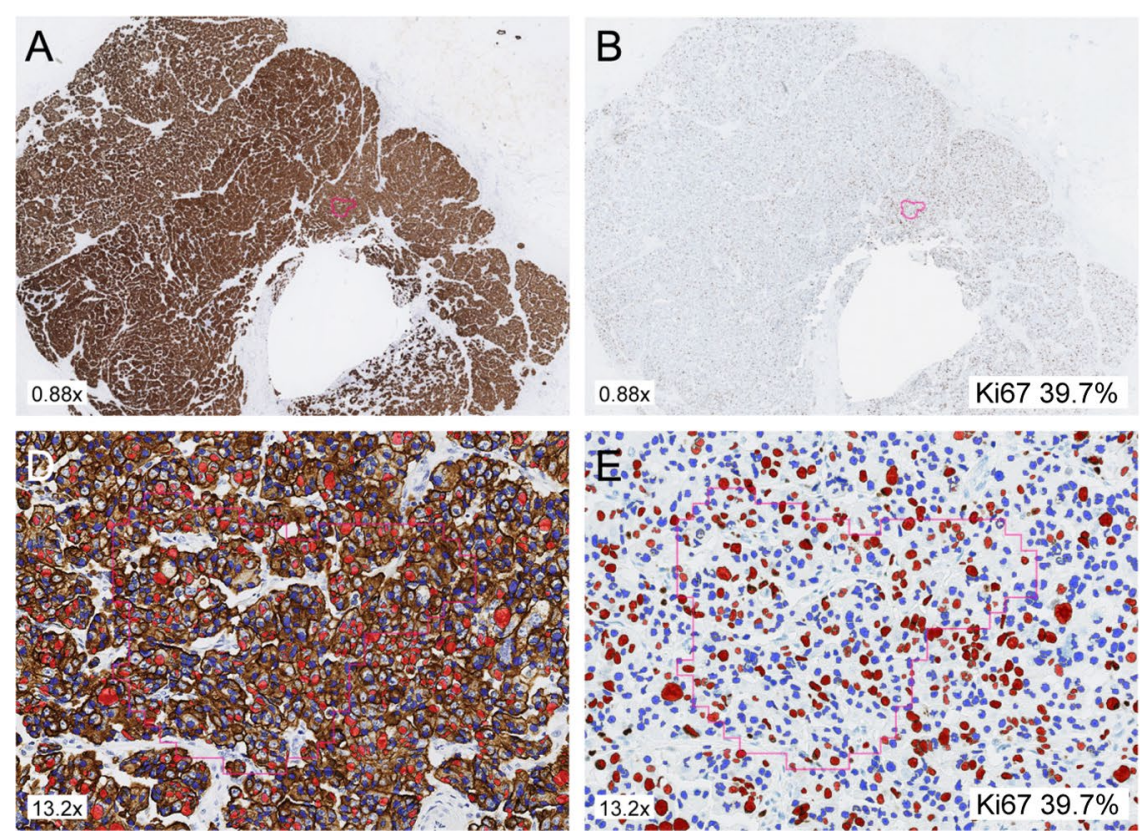
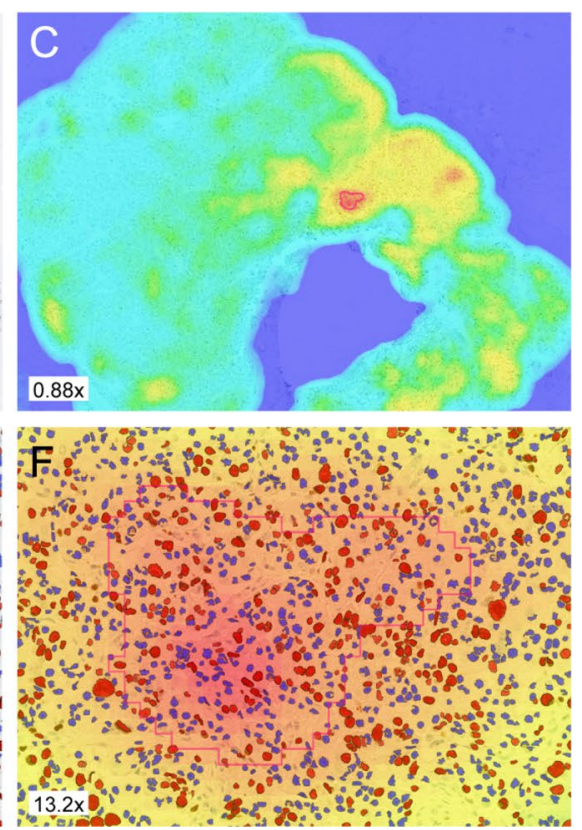

Fig. 1 CKMNF116 (a) and aligned Ki67 (b) immunohistochemistry stained tumor slide with automated hot spot detection (pink outline) using APP24. Corresponding heatmap illustrating the areas with highest Ki67\% score (c). Tumor cell detection and hot spot region visualized in CKMNF116 (d), Ki67 (e) and heatmap (f). Ki67-positive cells marked in red and Ki67-negative cells in blue 
Table 1 Hot spot app characteristics with the four configurable parameters: number of cells in the hot spot, heatmap and drawing radius ( $20 \times$ or $40 \times$ field of view), heatmap based on positive cells or on positive ratio, and hot spot shape (circle or contour heatmap)

\begin{tabular}{|c|c|c|c|c|}
\hline Hot spot app & $\begin{array}{l}\text { Tumor cell } \\
\text { count }\end{array}$ & Radius & Positive/ratio & Shape \\
\hline APP02 & 200 & $40 \times$ & Pos & Circle \\
\hline APP03 & 1000 & $20 x$ & Pos & Circle \\
\hline APP04 & 200 & $20 \times$ & Pos & Circle \\
\hline APP05 & 1000 & $20 x$ & Ratio & Circle \\
\hline APP06 & 200 & $20 \times$ & Ratio & Circle \\
\hline APP08 & 200 & $40 \times$ & Ratio & Circle \\
\hline APP09 & 1000 & $20 \times$ & Pos & $\begin{array}{l}\text { Contour } \\
\text { heatmap }\end{array}$ \\
\hline APP10 & 200 & $20 \times$ & Pos & $\begin{array}{l}\text { Contour } \\
\text { heatmap }\end{array}$ \\
\hline APP11 & 1000 & $40 \times$ & Pos & $\begin{array}{l}\text { Contour } \\
\text { heatmap }\end{array}$ \\
\hline APP12 & 200 & $40 \times$ & Pos & $\begin{array}{l}\text { Contour } \\
\text { heatmap }\end{array}$ \\
\hline APP13 & 1000 & $20 x$ & Ratio & $\begin{array}{l}\text { Contour } \\
\text { heatmap }\end{array}$ \\
\hline APP14 & 200 & $20 \times$ & Ratio & $\begin{array}{l}\text { Contour } \\
\text { heatmap }\end{array}$ \\
\hline APP15 & 1000 & $40 \times$ & Ratio & $\begin{array}{l}\text { Contour } \\
\text { heatmap }\end{array}$ \\
\hline APP16 & 200 & $40 \times$ & Ratio & $\begin{array}{l}\text { Contour } \\
\text { heatmap }\end{array}$ \\
\hline APP20 & 400 & $40 x$ & Ratio & $\begin{array}{l}\text { Contour } \\
\text { heatmap }\end{array}$ \\
\hline APP21 & 600 & $40 \times$ & Ratio & $\begin{array}{l}\text { Contour } \\
\text { heatmap }\end{array}$ \\
\hline APP22 & 800 & $40 \times$ & Ratio & $\begin{array}{l}\text { Contour } \\
\text { heatmap }\end{array}$ \\
\hline APP23 & 1200 & $40 \times$ & Ratio & $\begin{array}{l}\text { Contour } \\
\text { heatmap }\end{array}$ \\
\hline APP24 & 400 & $40 x$ & Pos & $\begin{array}{l}\text { Contour } \\
\text { heatmap }\end{array}$ \\
\hline APP25 & 600 & $40 \times$ & Pos & $\begin{array}{l}\text { Contour } \\
\text { heatmap }\end{array}$ \\
\hline APP26 & 800 & $40 x$ & Pos & $\begin{array}{l}\text { Contour } \\
\text { heatmap }\end{array}$ \\
\hline APP27 & 1200 & $40 \times$ & Pos & $\begin{array}{l}\text { Contour } \\
\text { heatmap }\end{array}$ \\
\hline
\end{tabular}

$40 \times$ field of view, which generated a diameter of $1.04 \mathrm{~mm}$ or $0.52 \mathrm{~mm}$, with a radius of $0.52 \mathrm{~mm}$ or $0.26 \mathrm{~mm}$, respectively.

The ratio heatmap takes both Ki67-positive and negative tumor cells into account, and a threshold can be set to indicate the minimum number of cells needed for it to be considered a hot spot. This can then be combined with the heatmap to only show hot spots with the set minimum number of cells. Notably, ratio heatmaps can have tendencies to show hot spots at the periphery of the tissue: partly putting the hot spot on the background area for the criteria to be met.
The two most relevant methods to set up the shape of the hot spot was by creating a circular hot spot or a hot spot that follows the contours of the heatmap. The circular hot spot corresponds to the field of view through a microscope. The contour heatmap hot spot also allows the hot spot to more closely follow the heatmap, and a smaller drawing radius should in general then be used.

The number of cells in the hot spot is influenced by several parameters. The heatmap can be limited to only show hot spots in areas with a minimum number of cells. As the area of the hot spot is fixed, the number of cells will vary depending on the tumor density, but a minimum number can be guaranteed through heatmap limiting. According to current guidelines, we initially set the minimum number of cells to either 200 or 1000 cells.

These four defined parameters were combined into 16 hot spot apps, namely APP01-16. APP01 and APP07 were excluded before analysis since the combination of 1000 cells and $40 \times$ radius was not appropriate here. Furthermore, additional APP20-27 were created combining either 400, 600, 800 or 1200 cells, and a total of 22 hot spot apps were created (Table 1). Each hot spot app provided a Ki67 score from a single hot spot for every tumor case it was run on. Depending on the app parameters, the location of the hot spot could vary across the tumor area for different apps run on the same tumor. Thus, the hot spot location may be either central or peripheral.

\section{Ki67 global scoring}

The QuPath (open source software [33]) platform was used to build an automated Ki67 scoring algorithm for the general Ki67 scoring in breast cancer. As the date of Ki67 staining varied within the cohort, we refined the immunohistochemical and hematoxylin stain estimates for each digitized slide (estimate stain vectors command in QuPath). We used watershed cell detection [34] to segment the cells in the image with the following settings: detection image, optical density sum; requested pixel size, $0.5 \mu \mathrm{m}$; background radius, $8 \mu \mathrm{m}$; median filter radius, $0 \mu \mathrm{m}$; sigma, $1.5 \mu \mathrm{m}$; minimum cell area, $10 \mu \mathrm{m}^{2}$; maximum cell area, $400 \mu \mathrm{m}^{2}$; threshold, 0.1 ; maximum background intensity, 2 . In order to classify detected cells into tumor cells, immune cells, stromal cells and others (false detections, background), we used random trees as a machine learning method [35] (Fig. 2). The features used in the classification are described in Supplementary Table S1. In order for the algorithm to perform an accurate classification, we also added smoothed object features at 25 and $50 \mu \mathrm{m}$ radius to supplement the existing measurements of individual cells. The quality control of the algorithm to classify detected cells was performed by a pathologist. The analysis was run on the entire tumor area on the whole slide defined by a pathologist and output as a global Ki67 score (\%). 

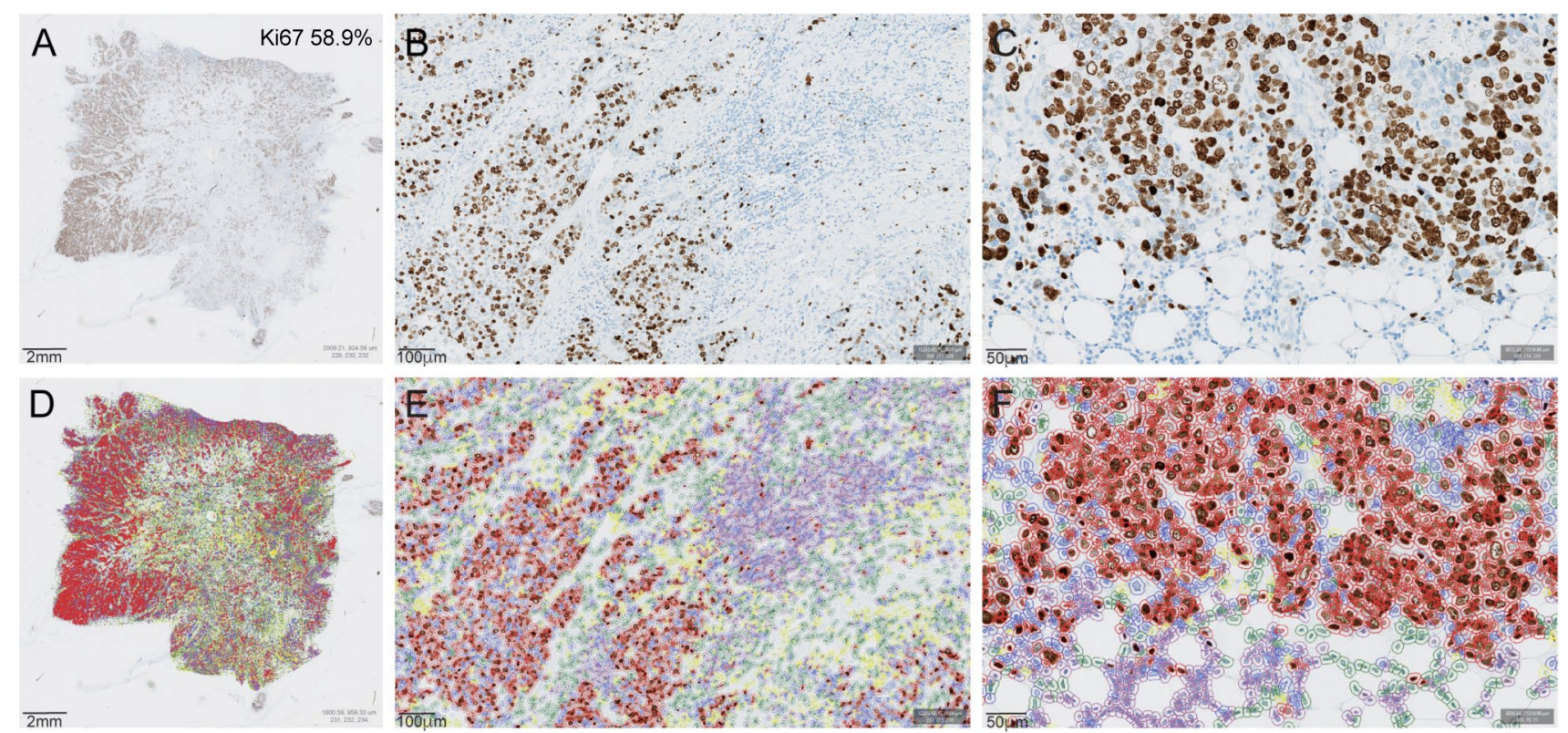

Fig. 2 Automated Ki67 scoring algorithm in QuPath illustrated by a Ki67 immunohistochemistry stained tumor slide $(\mathbf{a}-\mathbf{c})$ with the cell classifier (d-f) for global Ki67 scoring. Ki67-positive tumor cells marked in red, Ki67-negative tumor cells in blue, immune cells in purple, stromal cells in green and other cells in yellow $(\mathbf{d}-\mathbf{f})$
For global scoring the algorithm was trained only on Ki67 immunohistochemical staining and the training was performed on 500 cells in an independent training cohort of 30 ER+ breast cancer tumors. Regarding global Ki67 scoring, $a \geq 20 \%$ cut-off was used for distinguishing high from low proliferation as recommended by the St Gallen 2013 [5].

\section{Statistical analysis}

Normal distribution was tested by Kolmogorov-Smirnov test of normality, and non-parametric methods were used for significance testing. The intraclass correlation coefficient was used to test reproducibility using log-transformed Ki67 values. The agreement between Ki67 values by DIA hot spot and DIA global scoring was assessed in a Bland-Altman plot. The Kaplan-Meier method was used for survival analysis of OS and RFS, and compared using log-rank test. The Cox proportional hazard model for univariate and multivariate analysis was used for analysis of prognostic potential. McNemar test for categorical paired variables and Cohen's $\kappa$ test for scoring and subtype agreement were used. The statistical analysis was performed using IBM SPSS Statistics version 25 (IBM Corporation, Armonk, NY, USA). $p$ values $<0.05$ were considered significant. Power analysis was calculated and was set to $\geq 0.80$.

\section{Results}

Of the 217 tumors available for DIA, a total of 48 cases were excluded after strict criteria and pathologist review (Supplementary Fig. S1). The excluded cases were either due to no invasive tumor in slide $(n=2)$, poor immunohistochemical staining $(n=4)$, misalignment $(n=2)$, hot spot detected in artifacts $(n=16)$ or in ductal carcinoma in situ components $(n=11)$, or other errors in analysis $(n=13)$. Only cases with successful DIA scores for all 22 apps were included for further analysis $(n=169)$. Among these cases, 139 were identified as ER+/HER2-, thus classified as luminal A-like or luminal B-like (HER2-) tumors and included in all further analysis (Table 2). The median follow-up time for RFS was 8.7 years (range $0.3-14.7$ years) and 9.1 years for OS (range 2.1-14.8 years). The median Ki67 score by DIA hot spot apps ranged from 21.6 to $35.7 \%$. The median Ki67 score by manual and DIA global scoring was $20.0 \%$ and $15.9 \%$, respectively (Fig. 3).

\section{Automated Ki67 scoring}

Applying different hot spot apps on the same tumor whole slide image shows variations in heatmap pattern and region of detected hot spot as illustrated in Fig. 4. The distribution of number of cells scored for each app 
Table 2 Patient and tumor characteristics

\begin{tabular}{|c|c|c|}
\hline & No. & $\%$ \\
\hline Total no. of tumors & 139 & 100 \\
\hline Patient mean age at diagnosis (years) & 59 & - \\
\hline \multicolumn{3}{|l|}{ Histological subtype } \\
\hline Ductal/no special type & 112 & 80.6 \\
\hline Lobular & 16 & 11.5 \\
\hline Other & 11 & 7.9 \\
\hline \multicolumn{3}{|l|}{ Nottingham histological grade } \\
\hline Grade 1 & 21 & 15.1 \\
\hline Grade 2 & 72 & 51.8 \\
\hline Grade 3 & 44 & 31.7 \\
\hline Unclassified & 2 & 1.4 \\
\hline \multicolumn{3}{|l|}{ Tumor size $(\mathrm{mm})$ and $\mathrm{pT}^{*}$} \\
\hline$\leq 20, \mathrm{pT} 1$ & 55 & 39.6 \\
\hline$>20$ and $\leq 50, \mathrm{pT} 2$ & 76 & 54.7 \\
\hline$>50, \mathrm{pT} 3$ & 8 & 5.8 \\
\hline \multicolumn{3}{|l|}{ No. of positive lymph nodes and $\mathrm{pN}^{*}$} \\
\hline $0, \mathrm{pN} 0$ & 76 & 54.7 \\
\hline $1-3, \mathrm{pN} 1$ & 45 & 32.4 \\
\hline $4-9, \mathrm{pN} 2$ & 13 & 9.4 \\
\hline$\geq 10, \mathrm{pN} 3$ & 5 & 3.6 \\
\hline \multicolumn{3}{|l|}{ Estrogen receptor (\%) } \\
\hline$\geq 1$ and $<10$ & 0 & 0.0 \\
\hline$\geq 10$ & 132 & 95.0 \\
\hline Positive by other method & 7 & 5.0 \\
\hline \multicolumn{3}{|l|}{ Progesterone receptor (\%) } \\
\hline$<20$ & 36 & 25.9 \\
\hline$\geq 20$ & 99 & 71.2 \\
\hline Positive by other method & 4 & 2.9 \\
\hline \multicolumn{3}{|l|}{ Ki67 (\%) } \\
\hline$<20$ & 59 & 42.4 \\
\hline$\geq 20$ & 70 & 50.4 \\
\hline Unknown numerical value & 10 & 7.2 \\
\hline \multicolumn{3}{|l|}{ IHC-based surrogate subtype } \\
\hline Luminal A-like & 47 & 33.8 \\
\hline Luminal B-like (HER2-) & 82 & 59.0 \\
\hline LumA/LumB unknown Ki67 value & 10 & 7.2 \\
\hline \multicolumn{3}{|l|}{ PAM50 intrinsic subtype } \\
\hline Luminal A & 79 & 56.8 \\
\hline Luminal B & 30 & 21.6 \\
\hline HER2-enriched & 1 & 0.7 \\
\hline Basal-like & 1 & 0.7 \\
\hline Unclassified & 28 & 20.1 \\
\hline \multicolumn{3}{|l|}{ Neoadjuvant treatment } \\
\hline Endocrine therapy & 1 & 0.72 \\
\hline \multicolumn{3}{|l|}{ Adjuvant treatment } \\
\hline Chemotherapy & 54 & 38.8 \\
\hline Endocrine therapy & 118 & 84.9 \\
\hline Radiotherapy & 89 & 64.0 \\
\hline Anti-HER2 therapy & 0 & 0.0 \\
\hline Unclassified & 18 & 12.9 \\
\hline
\end{tabular}

Table 2 (continued)

\begin{tabular}{lcc}
\hline & No. & $\%$ \\
\hline Outcome & & \\
Patients with recurrence at end follow-up & 28 & 20.1 \\
5-year recurrence-free survival rate (\%) & & 82.9 \\
10-year recurrence-free survival rate (\%) & & 57.1 \\
Patients dead at end follow-up & 20 & 14.4 \\
5-year overall survival rate (\%) & & 94.3 \\
10-year overall survival rate (\%) & & 67.7 \\
\hline
\end{tabular}

*Pathologic T stage (pT) for invasive tumor and pathologic N stage $(\mathrm{pN})$ for regional lymph nodes according to AJCC Breast Cancer Staging 7th Edition (TNM 7)

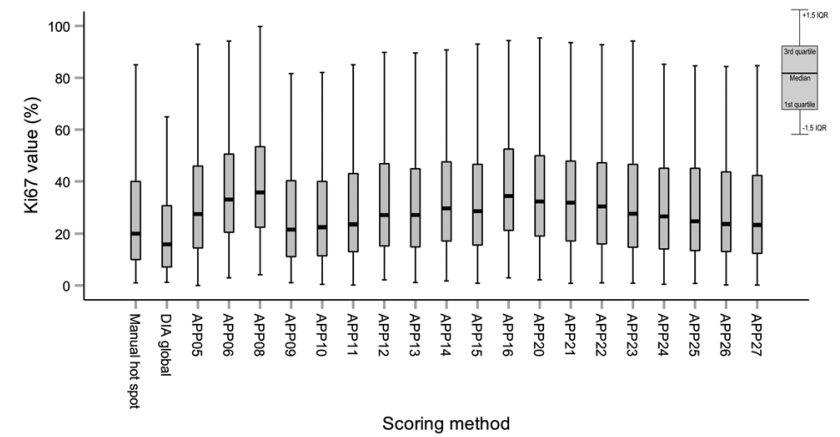

Fig. 3 Ki67 distribution for luminal-like tumors $(n=139)$ scored by manual hot spot, DIA global or DIA hot spot apps (APP05-27). Box plot illustrating median, interquartile range and range. DIA digital image analysis, $I Q R$ interquartile range

included is shown in Fig. 5 and Supplementary Fig. S2. The extreme outliers APP03 (median 2366 cells, range 76-5965 cells) and APP04 (median 2366 cells, range 588-5965 cells) were excluded since the range of number of cells far exceeded the set included cell count of 1000 and 200 cells, respectively. APP02 was also excluded due to cell count far exceeding the defined 200 cells (median 715 cells, range 199-1629 cells). After exclusion, 19 different apps remained for analysis.

The intraclass correlation coefficient among apps with low cell counts around 200 cells (APP06, 08, 10, 12, 14, 16) was 0.858 [confidence interval (CI) 0.768-0.918]. For apps with 400-800 cells (APP20, 21, 22, 24, 25, 26), the intraclass correlation coefficient was 0.956 (CI 0.919-0.973), and 0.959 (CI 0.935-0.973) among apps with high cell counts, around 1000 cells (APP05, 09, 13, $23,27)$. Consequently, the higher the scored cell counts, the greater the reproducibility of Ki67 values. The median tumor cell counts with DIA global scoring in QuPath was 97,940 cells (range 9550-1,055,427 cells). A Bland-Altman plot for comparison of the agreement of Ki67 values 

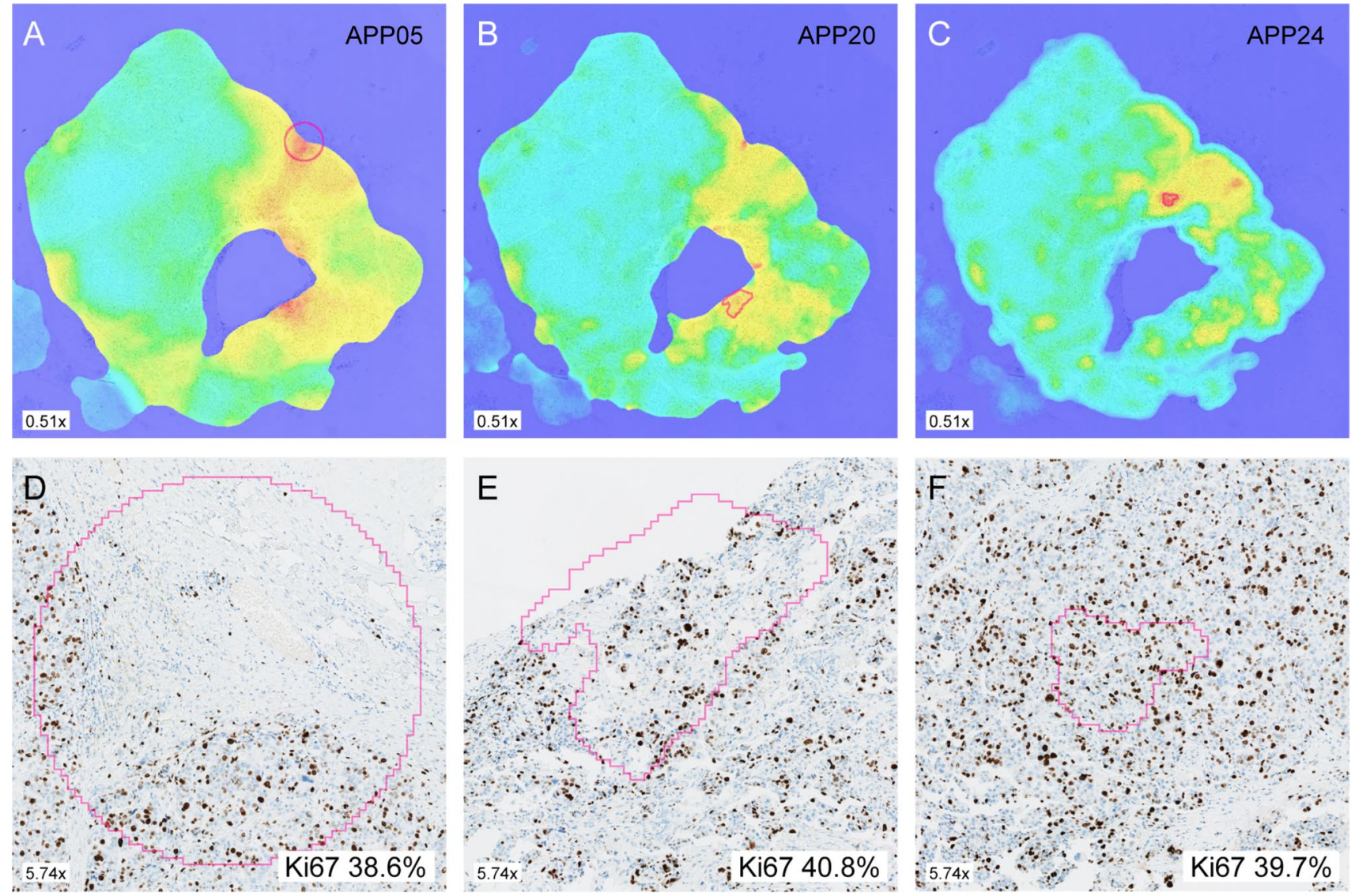

Fig. 4 Heatmaps from the same tumor showing different Ki67 hot spot areas (pink outline) using APP05 (a), APP20 (b) and APP24 (c). Hot spots (pink outline) with Ki67 values for each corresponding app (a-c) are illustrated in $\mathbf{d}-\mathbf{f}$, respectively

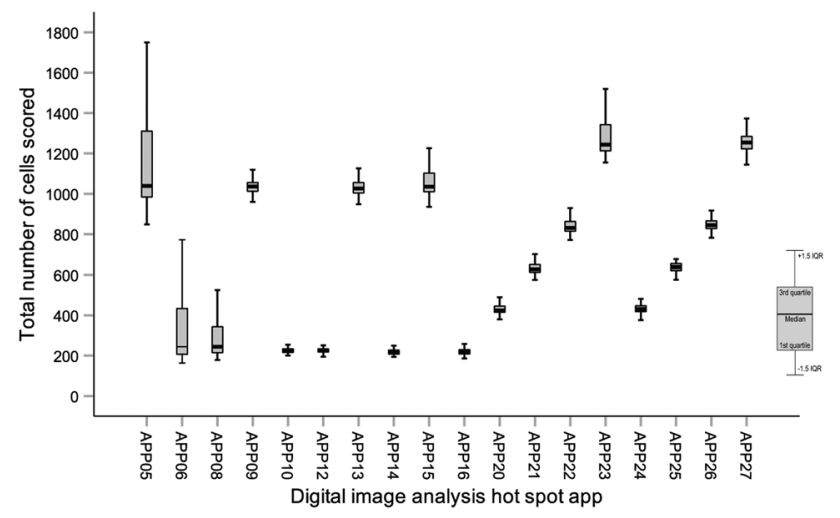

Fig. 5 Box plot illustrating the distribution of the number of cells scored for each hot spot app included. IQR interquartile range

by hot spot APP24 and DIA global scoring showed systematic differences between the two methods $(p<0.0001$; regression slope $p<0.0001$, intercept $p=0.0004$; Supplementary Fig. S3).

\section{Prognostic potential for hot spot versus global scoring}

Regarding prognostic potential, the following apps showed the highest hazard ratios (HR) for RFS: APP10, 11, 15, 23, 24 and 26 (Supplementary Table S2). APP24 reached the highest prognostic potential among hot spot apps for RFS (HR 6.88, CI 2.07-22.87, $p=0.002$ ), compared to global Ki67 scoring with a HR of 3.13 (CI 1.41-6.96, $p=0.005$ ) (Fig. 6). Cox regression HR for OS and high versus low Ki67 was highest with APP27 (HR 8.42, CI 1.95-36.35, $p=0.004$ ); however, APP24 (HR 6.93, CI 1.61-29.91, $p=0.009$ ) was slightly inferior to global Ki67 scoring (HR 7.46, CI 2.46-22.58, $p<0.001$ ) (Supplementary Table S2). Manual Ki67 hot spot scoring was only significant for RFS (HR 2.76, CI 1.16-6.53, $p=0.021$ ) (Supplementary Table S2 and Fig. S4).

The prognostic value was further investigated among node-negative (pN0) patients and those with 1-3 axillary lymph node metastases (pN1). Survival analysis with Kaplan-Meier estimates showed significant difference in OS and RFS among pN0 cases with high versus low Ki67 

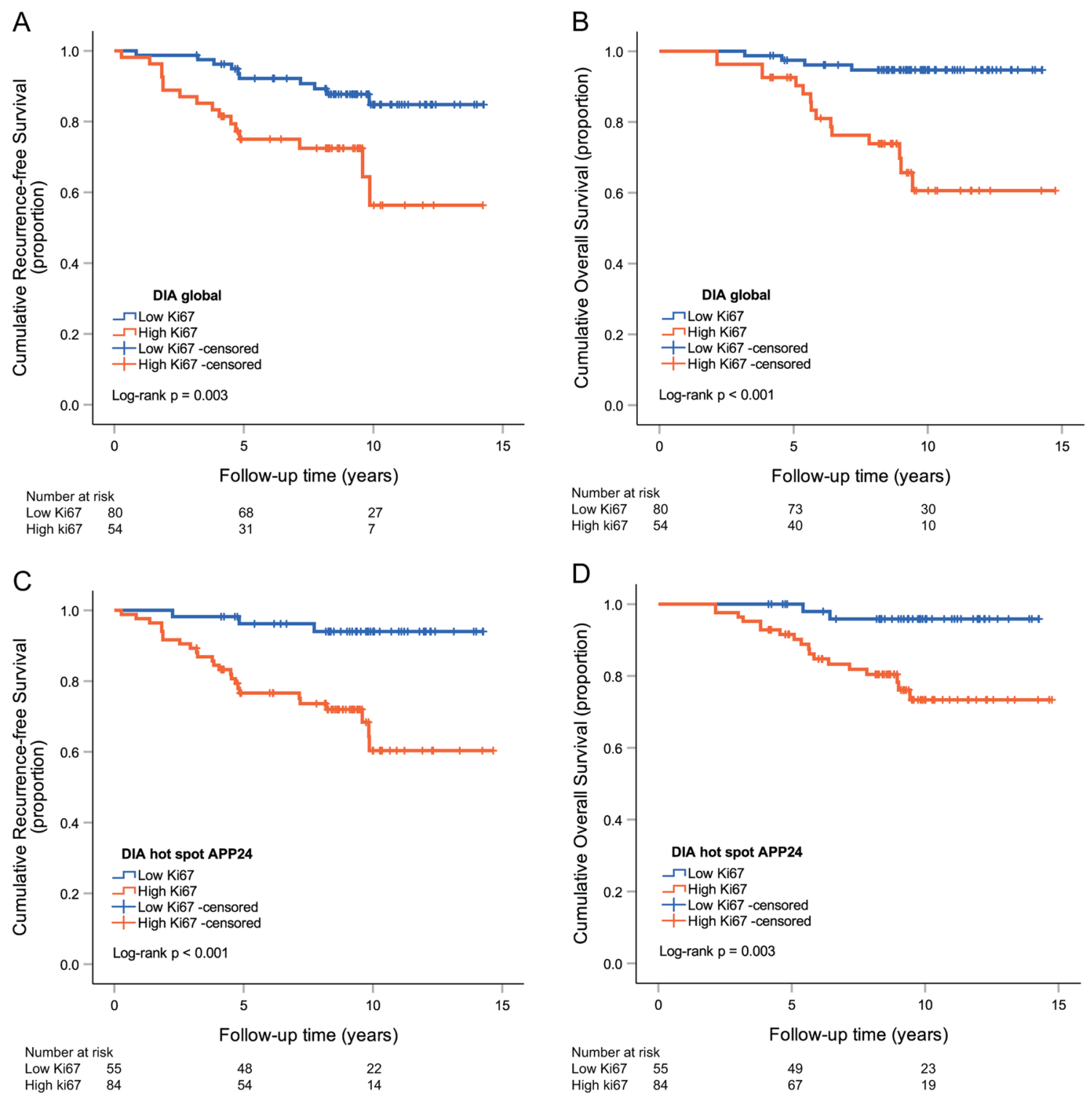

Fig. 6 Kaplan-Meier curves demonstrating associations between low versus high Ki67 subgroups and recurrence-free survival (a) or overall survival (b) using global scoring. Kaplan-Meier curves dem-

scored by the global scoring method and in RFS using hot spot APP24 (Supplementary Fig. S5, S6). Further, among pN0 cases, the HR for RFS was significantly increased in high versus low Ki67 cases scored by the global method (HR 4.12, CI 1.01-16.74, $p=0.048$ ). No significant differences in HR for RFS among pN1 cases or in OS among $\mathrm{pN} 0$ and $\mathrm{pN} 1$ patients was shown by any scoring methods (Supplementary Table S3 and Fig. S5, S6). When cases were stratified for grade 1 tumors, no increased HR for OS (APP24 HR 0.04, $p=0.756$; global HR 0.04, $p=0.814$ ) was identified and notably all grade 1 cases were free from recurrence. We also stratified for mitotic score $1(n=62)$,

onstrating associations between low versus high Ki67 subgroups and recurrence-free survival (c) or overall survival (d) using hot spot APP24 Ki67 scoring. DIA digital image analysis

and the HR for RFS was significantly increased in high versus low Ki67 cases using DIA hot spot scoring (HR 5.05, CI 1.26-20.25, $p=0.022$ ), but not with DIA global scoring (HR 5.01, CI 0.90-27.95, $p=0.066$ ). Here, there was no significant increased risk for death in Ki67 high vs low cases using any of the scoring methods (APP24 HR 6.80, $p=0.97$; global HR 3.94, $p=0.263$ ).

Kaplan-Meier analysis for RFS with hot spot Ki67 scoring reached a power of 0.90 and a power of 0.95 for OS with global scoring. Global scoring for RFS (power $<0.80$ ) and hot spot scoring for OS (power $<0.80$ ) was not considered powered enough. 


\section{IHC-based surrogate subtypes versus PAM50 subtypes}

PAM50 intrinsic subtypes were available for 111 tumors out of which 79 were luminal A (71.2\%), 30 luminal B (27.0\%), one was basal-like (1.0\%) and one was HER2-enriched (1.0\%; Table 2). For subtype comparisons, only luminal A and B tumors were included $(n=109)$. We used hot spot APP24 Ki67 scores and global Ki67 scores for IHC-based surrogate subtype classification with a 20\% cut-off for Ki67. Based on Ki67 values from hot spot APP24, 39 tumors were classified as luminal A-like (30.0\%) and 93 tumors as luminal B-like (70.5\%). Among 104 tumors with PAM50 subtype data and surrogate subtype based on hot spot Ki67 scores, 58 tumors had concordant subtype $(55.8 \%, \kappa=0.250)$. When global Ki67 values were used, 62 tumors were classified as luminal A-like (48.4\%) and 66 as luminal B-like (51.6\%). Here, among 101 tumors with PAM50 subtype and surrogate subtype based on global Ki67 scores, 67 tumors hade concordant subtype $(66.3 \%, \kappa=0.345)$.

Patients with luminal B tumors (PAM50 subtype) had significantly higher hazard ratios for recurrence (HR 2.636, CI 1.180-5.892, $p=0.018$ ) and death (HR 4.050, CI $1-541-10.647, p=0.005)$ as compared to those with luminal A tumors (Supplementary Fig. S7). When tumors were divided in luminal A-like and luminal B-like using hot spot Ki67, Kaplan-Meier estimates showed a significant worse RFS (log-rank $p=0.002)$ and OS (log-rank $p=0.011)$ for patients with luminal B-like tumors (Supplementary Fig. S7). The HR was 12.351 for RFS (CI 1.676-91.032, $p=0.014$ ) and 8.648 (CI 1.158-64.6, $p=0.035$ ) for OS in luminal B-like versus luminal A-like cases, and no further conclusions are made due to the broad CI. Applying global Ki67 for surrogate subtypes, did not provide any significant difference between luminal B-like and luminal A-like cases with regard to RFS (HR 1.899, CI 0.834-4.302, $p=0.124$ ). On the other hand, there was a significantly increased HR for OS (HR 5.947, CI 1.731-20.434, $p=0.005$ ) in luminal B-like versus luminal A-like cases (Supplementary Fig. S7).

\section{Multivariate Cox regression analysis}

To further investigate the individual prognostic potential of hot spot APP24, DIA global and manual hot spot scoring, we performed a multivariate Cox regression analysis. The categorical covariates tumor size (pT1, pT2, pT3), tumor Nottingham histological grade $(1,2,3)$, mitotic score $(1$, 2,3 ) and lymph node status (pN0, pN1 or pN0, pN1, pN2, $\mathrm{pN} 3$, respectively) were tested in univariate Cox regression analyses, out of which only lymph node status including pN0/1/2/3 was significantly ( $p=0.005)$ associated to RFS (Supplementary Table S4). Regarding the clinically relevant $\mathrm{pN} 0$ and $\mathrm{pN} 1$ cases, lymph node status was, however, not significant in univariate analysis $(p=0.208)$. A multivariate Cox proportional hazards regression model was fitted to RFS time of the 139 cases. Adjusting the model to lymph node status (pN0/1), DIA global scoring (HR 3.53, CI 1.21-9.54, $p=0.013$ ) and manual hot spot scoring $(p=0.036)$ remained significantly associated with RFS (Table 3). In the multivariate model, the HR for RFS using DIA hot spot scoring resulted in an unreliably broad CI (HR 13.80, CI 1.83-104.05, $p=0.011$ ). Adding lymph node status including $\mathrm{pN} 2 / 3$ cases to the multivariate model, all scoring methods remained significantly associated with RFS (APP24 $p=0.001$, global DIA $p=0.004$ and manual hot spot $p=0.022$ ) (Supplementary Table S5).

Turning to OS, only the categorical covariates tumor grade $(1,2,3)$ and mitotic score $(1,2,3)$ was significantly associated with OS in univariate analysis $(p<0.001$ and $p=0.009$, respectively). Regarding the clinically relevant pN0 and pN1 cases, lymph node status was not significant in univariate analysis ( $p=0.114$; Supplementary Table S6). The multivariate Cox regression model was fitted to OS time, adjusting for grade, mitotic score and lymph node status (pN0/1). When each of the three Ki67 scoring methods was added to the model, only global Ki67 scoring remained significant (HR 7.11, CI 1.09-46.46, $p=0.040$ ) in the multivariate analysis associated to OS (Table 4). The HR for OS using DIA global scoring remained significant and with a

Table 3 Multivariate Cox proportional hazard models for recurrence-free survival

\begin{tabular}{|c|c|c|c|}
\hline Variables in model & Hazard ratio & $95 \%$ confidence interval & $p$ \\
\hline $\mathrm{pN}$ stage $^{\mathrm{a}}(\mathrm{pN} 1$ vs pN0) & 1.99 & $0.79-5.03$ & 0.144 \\
\hline Ki67 DIA hot spot APP24 scoring ( $\geq 20 \%$ vs $<20 \%$ ) & 13.80 & $1.83-104.05$ & $0.011^{*}$ \\
\hline pN stage (pN0 vs pN1) & 1.54 & $0.61-3.90$ & 0.361 \\
\hline Ki67 DIA global scoring ( $\geq 20 \%$ vs $<20 \%$ ) & 3.53 & $1.31-9.54$ & $0.013 *$ \\
\hline pN stage (pN0 vs pN1) & 1.44 & $0.57-3.65$ & 0.438 \\
\hline Ki67 manual hot spot scoring ( $\geq 20 \%$ vs $<20 \%$ ) & 3.31 & $1.08-10.11$ & $0.036^{*}$ \\
\hline
\end{tabular}

DIA digital image analysis

${ }^{*} p$ significant at $\mathrm{a}<0.05$ level

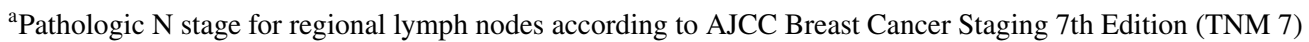


Table 4 Multivariate Cox proportional hazard models for overall survival

\begin{tabular}{|c|c|c|c|}
\hline Variables in model & Hazard ratio & $95 \%$ confidence interval & $p$ \\
\hline Grade (1 ref) & - & - & - \\
\hline Grade 2 & 0.92 & $0.08-10.80$ & 0.949 \\
\hline Grade 3 & 10.55 & $0.39-287.98$ & 0.163 \\
\hline Mitotic score (1 ref) & - & - & - \\
\hline Mitotic score 2 & 0.42 & $0.04-4.85$ & 0.487 \\
\hline Mitotic score 3 & 0.21 & $0.01-3.64$ & 0.284 \\
\hline $\mathrm{pN}_{\text {stage }}{ }^{\mathrm{a}}(\mathrm{pN} 1 \mathrm{vs} \mathrm{pN} 0)$ & 2.28 & $0.73-7.14$ & 0.158 \\
\hline Ki67 DIA hot spot APP24 scoring ( $\geq 20 \%$ vs $<20 \%$ ) & 2.93 & $0.50-17.35$ & 0.236 \\
\hline Grade (1 ref) & - & - & - \\
\hline Grade 2 & 1.05 & $0.09-11.62$ & 0.971 \\
\hline Grade 3 & 6.25 & $0.23-171.59$ & 0.278 \\
\hline Mitotic score (1 ref) & - & - & - \\
\hline Mitotic score 2 & 0.30 & $0.03-3.70$ & 0.348 \\
\hline Mitotic score 3 & 0.19 & $0.01-3.40$ & 0.261 \\
\hline $\mathrm{pN}$ stage $^{\mathrm{a}}(\mathrm{pN} 1 \mathrm{vs} \mathrm{pN} 0)$ & 1.87 & $0.61-5.75$ & 0.277 \\
\hline Ki67 DIA global scoring $(\geq 20 \%$ vs $<20 \%)$ & 7.11 & $1.09-46.46$ & $0.040^{*}$ \\
\hline Grade (1 ref) & - & - & - \\
\hline Grade 2 & 1.09 & $0.10-12.06$ & 0.944 \\
\hline Grade 3 & 13.32 & $0.51-348.73$ & 0.120 \\
\hline Mitotic score (1 ref) & - & - & - \\
\hline Mitotic score 2 & 0.70 & $0.06-8.23$ & 0.778 \\
\hline Mitotic score 3 & 0.50 & $0.03-9.40$ & 0.645 \\
\hline $\mathrm{pN}_{\text {stage }}^{\mathrm{a}}(\mathrm{pN} 1 \mathrm{vs} \mathrm{pN} 0)$ & 1.60 & $0.51-5.01$ & 0.423 \\
\hline Ki67 manual hot spot scoring ( $\geq 20 \%$ vs $<20 \%$ ) & 0.72 & $0.20-2.65$ & 0.620 \\
\hline
\end{tabular}

DIA digital image analysis

* $p$ significant at a $<0.05$ level

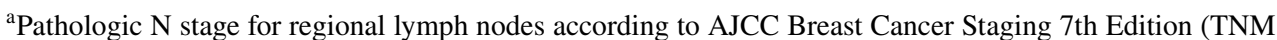
7)

narrower $\mathrm{CI}$ in the model adjusted for only grade and mitotic score (HR 5.44, CI 1.15-25.69, $p=0.032$ ).

\section{Categorical Ki67 score comparison}

McNemar test for categorical paired variables showed significant difference between DIA hot spot APP24 and global Ki67 scorings $(p<0.001)$. The agreement for low and high Ki67 grouping using hot spot and global scoring showed a $\kappa$ value of 0.54 , referred to as moderate agreement.

\section{Discussion}

We compare several different DIA hot spot apps with DIA global scoring using virtual dual staining versus traditional immunohistochemistry for DIA in a cohort of luminal-like tumors. Despite the established prognostic and predictive value of Ki67 for patients with HR+/HER2- tumors [4, 36], there is a lack of international expert consensus regarding assessment methods and standardization for Ki67 evaluation
$[5,17,20]$. Pre-analytical and analytical aspects along with poor interlaboratory scoring reproducibility are some of the identified causes of variability in Ki67 assessment, which has limited the international adoption in clinical breast cancer management $[18,19,21]$. There is increasing evidence suggesting that global or average scoring of Ki67 is favorable over hot spot scoring methods, and here Leung et al. suggest against the use of manual Ki67 hot spot scoring due to poor reproducibility $[37,38]$. The IKWG also point to the methodological aspects for improvement of Ki67 assessment $[24,38]$. In a study by Jang et al. manual average and hot spot methods for Ki67 scoring among HR+/HER2 - tumors was compared and both methods showed good predictive performances for recurrence; however, the average method showed higher reproducibility [39].

The European Society of Medical Oncology Clinical Practice Guidelines point out the importance of standardization of Ki67 scoring. By recommending IHC-based surrogate intrinsic subtype classification of tumors they indirectly imply the use of Ki67 [40]. The St Gallen consensus of 2019 supports the use of gene expression signature assays 
for patients with $\mathrm{ER}+$ tumors with $<3$ positive lymph nodes to determine the benefit of additional chemotherapy. When gene expression signatures are not available, surrogate subtyping may be based on a combination of grade, ER/PR and Ki67 [41]. The recommendations from the Breast Committee of the German Gynecological Oncology Group (AGO) are in line, and do not provide any specific guidelines for Ki67 scoring but mention Ki67 for distinguishing luminal B-like tumors [42]. On the contrary, the American Society of Clinical Oncology Clinical Practice Guideline concludes that there is insufficient evidence to recommend the use of Ki67 for choice of adjuvant chemotherapy [43, 44]. As proposed by the St Gallen consensus in 2013, laboratoryspecific cut-offs for Ki67 are used in Sweden since 2018 [5]. According to Maisonneuve et al. Ki67 is categorized into three groups: low, intermediate and high proliferation, where PR has importance for dichotomizing the intermediate Ki67 group into luminal A-like and luminal B-like tumors [16]. This has been adopted by the Swedish guidelines and low Ki67 is defined as $<15 \%$, intermediate Ki67 as $15-22 \%$ and high Ki67 $\geq 23 \%$ at our institution (Department of Clinical Pathology, Karolinska University Laboratory) [22]. Similar to the Swedish guidelines, the Danish Breast Cancer Cooperative Group recommends Ki67 to be scored in hot spots, but also in the invasive tumor fronts and in 5-10\% intervals [45]. External quality assurance programs (e.g., NordiQC) for immunohistochemical assessments and frequent monitoring are important measures to continuously improve the quality of Ki67 scoring [46]

Computerized image analysis is rapidly emerging and has potential to improve biomarker assessment. We have previously reported that automated DIA for Ki67 scoring outperforms manual scoring, and that DIA hot spot Ki67 scoring was the superior method for distinguishing luminal A-like from B-like tumors [26, 27]. Apart from conventional machine learning methods, Saha et al. reported high precision using a deep learning approach for automated Ki67 hot spot scoring on immunohistochemically stained breast tumor images compared to manual scoring [47]. The reproducibility of automated scoring was recently investigated in a multicenter study by the IKWG and suggests that automated average Ki67 scoring methods hold promise but require standardization and clinical validation [24]. Furthermore, excellent reproducibility of Ki67 evaluation across different DIA platforms, including QuPath, has recently been shown, as well as how DIA can be standardized to improve Ki67 scoring [23].

In our study, we investigated different configurable parameters for defining a digital hot spot region with regards to prognostic potential. To date there is no clinically validated recommendations for hot spot definitions with automated scoring methods. When our DIA hot spot apps were grouped based on total cell counts, we show that the reproducibility of Ki67 scores depends on the investigated cell numbers. The larger the number of investigated cells, the higher the reproducibility between the apps in the group. The median Ki67 value was higher across all DIA hot spot apps (21-35\%) and manual hot spot scoring (20\%) as compared to the global DIA Ki67 scoring (15.9\%), which is in line with previous published data [38].

The prognostic value of Ki67 can be used to distinguish patients in low and high Ki67 groups based on outcome. Among all the tested digital hot spot apps, our results showed that the selected DIA hot spot APP24, which was based on 400 cells, $40 \times$ field of view and a heatmap shaped hot spot, had twice as high hazard ratio for RFS compared to DIA global Ki67 scoring in univariate analysis. In this app (APP24), the hot spot was based on positive nuclei, which, however, does not consider the cell density. A dense area might contain a larger number of nuclei, and hence a larger number of positive nuclei, and have a lower percentage of positive cells than another more sparsely populated region. The heatmap shaped hot spot requires a minimum number of cells to be included. As the hot spot follows the shape of the heatmap it will sometimes include slightly more nuclei than the minimum number, but never less. Regarding HR for OS in the univariate model, DIA global scoring was superior to hot spot scoring, which was also shown among nodenegative cases. Furthermore, adjusted multivariate models showed that DIA global scoring had independent prognostic value for both RFS and OS, which was not shown for DIA hot spot Ki67 scoring.

Molecular subtyping of tumors based on, e.g., the PAM50 algorithm provides prognostic information, which was also confirmed in this study. In our cohort, the concordance of DIA Ki67-based subtypes and PAM50 subtypes was rather low, thus slightly greater using global Ki67 values as opposed to hot spot scores. Using Ki67 values from both hot spot and global DIA scoring for IHC-based surrogate subtyping in luminal A-like and luminal B-like tumors, only the global Ki67 method provided prognostic value for OS.

There are certain limitations to the study. The study cohort size is limited, which affected the power especially regarding outcome analysis. With the strict inclusion criteria, even cases which failed in only one app were excluded from analysis. Despite different platforms and methods for Ki67 scoring, we applied the same cut-off of $\geq 20 \%$ to define high proliferation in both the hot spot and global scoring. Some known prognostic clinicopathological factors, such as lymph node status was not significant in multivariate analysis for OS, most likely due to the rather low number of cases in each category. Since lymph node status is one of the most powerful prognostic factors in breast cancer, it was valuable to add $\mathrm{pN} 0 / 1$ to the multivariate adjusted model for both RFS and OS. Moreover, the patient cohort consists of a combination of both pre- and postmenopausal patients (age 
ranged from 28 to 79 years), since this was not a predefined inclusion criterion. Prognostic information based on surrogate IHC markers are mainly relevant for postmenopausal patients, which may be spared chemotherapy for those with luminal A-like tumors [48-50]. Regarding clinical utility in routine pathology, virtual dual staining with parallel sections stained for Ki67 and pancytokeratins is impractical and does not add any further value to the diagnostic process. By using more specific cytokeratins, e.g., dual staining with CK5 and CK18 instead of CKMNF116, thus also providing information regarding in situ components, which is often part of the routine work-up, the use of virtual dual staining could potentially be feasible for Ki67 scoring.

Despite these limitations, to our knowledge, this is the first study investigating the effect of different hot spot definitions on both reproducibility and prognostic potential, along with comparing the prognostic value of true global scoring, using two separate DIA platforms. This study showed similar prognostic potential using DIA hot spot and global Ki67 scoring, but only DIA global scoring was independently significant in adjusted multivariate analysis for both RFS and OS. Overall, we showed robust outcome prediction with DIA global Ki67 scoring in this ER+/HER2- cohort. Regarding clinical routine, DIA global Ki67 scoring based on only Ki67-stained sections is a more practical method than the virtual dual staining method for hot spot scoring. Based on our findings we can conclude that automated global Ki67 scoring is feasible and shows clinical validity. However, these findings need to be confirmed in a larger study cohort to prove clinical utility leading to clinical implementation.

Acknowledgements Open access funding provided by Karolinska Institutet. Visiopharm A/S did not offer any financial support or incentives, and solely contributed with technical support and use of the software. We are grateful for the constructive comments on the manuscript provided by Henrik Rossing at Visiopharm A/S. We thank Mattias Rantalainen at the Department of Medical Epidemiology and Biostatistics, Karolinska Institutet for providing molecular subtype data.

Author contributions Conceptualization: SR, BA and JH; Methodology: SR, BA and ML; Software: SR, BA and ML; Validation: SR and BA; Formal analysis: SR and BA; Investigation: SR, BA and JH; Resources: ML, and JH; Data curation: SR and BA; Writing-original draft preparation: SR; Writing-review and editing: BA, ML and JH; Visualisation: SR and BA; Supervision: JH; Project administration: SR and JH; Funding acquisition: JH. All authors read and approved the final manuscript.

Funding The study was supported by Grants from Swedish Cancer Society, MedTechLabs, Region Stockholm, Cancer Society in Stockholm, Swedish Breast Cancer Association and Swedish Society for Medical Research.

\section{Compliance with ethical standards}

Conflict of interest JH was former member of the advisory board at Visiopharm A/S. JH has obtained speaker's honoraria or advisory board remunerations from Roche, Novartis, AstraZeneca, Eli Lilly and MSD. $\mathrm{JH}$ is co-founder and shareholder of Stratipath AB. JH has received institutional research grants from Cepheid and Novartis. ML is employee of Visiopharm A/S. SR and BA declare no conflict of interest.

Ethical approval All procedures performed in studies involving human participants were in accordance with the ethical standards of the institutional research committee (Regional Ethical Review Board at Karolinska Institutet, Stockholm, Sweden) and with the 1964 Helsinki Declaration and its later amendments or comparable ethical standards. The study was approved by the Regional Ethical Review Board in Stockholm, Sweden on November 13, 2013 (No. 2013/1833-31/2).

Informed consent The study was based on retrospective clinical data, and no additional patient consent was required in accordance to ethical approval. However, prior to surgery, all patients have approved storage of material in the Stockholm medical Biobank for clinical research purposes.

Open Access This article is licensed under a Creative Commons Attribution 4.0 International License, which permits use, sharing, adaptation, distribution and reproduction in any medium or format, as long as you give appropriate credit to the original author(s) and the source, provide a link to the Creative Commons licence, and indicate if changes were made. The images or other third party material in this article are included in the article's Creative Commons licence, unless indicated otherwise in a credit line to the material. If material is not included in the article's Creative Commons licence and your intended use is not permitted by statutory regulation or exceeds the permitted use, you will need to obtain permission directly from the copyright holder. To view a copy of this licence, visit http://creativecommons.org/licenses/by/4.0/.

\section{References}

1. Gerdes J, Lemke H, Baisch H, Wacker HH, Schwab U, Stein H (1984) Cell cycle analysis of a cell proliferation-associated human nuclear antigen defined by the monoclonal antibody Ki-67. J Immunol 133:1710-1715

2. Colozza M, Azambuja E, Cardoso F, Sotiriou C, Larsimont D, Piccart MJ (2005) Proliferative markers as prognostic and predictive tools in early breast cancer: where are we now? Ann Oncol 16:1723-1739. https://doi.org/10.1093/annonc/mdi352

3. De Azambuja E, Cardoso F, de Castro G, Colozza M, Mano MS, Durbecq V, Sotiriou C, Larsimont D, Piccart-Gebhart MJ, Paesmans M (2007) Ki-67 as prognostic marker in early breast cancer: a meta-analysis of published studies involving 12,155 patients. $\mathrm{Br}$ J Cancer 96:1504-1513. https://doi.org/10.1038/sj.bjc.6603756

4. Yerushalmi R, Woods R, Ravdin PM, Hayes MM, Gelmon KA (2010) Ki67 in breast cancer: prognostic and predictive potential. Lancet Oncol 11:174-183. https://doi.org/10.1016/s1470 -2045(09)70262-1

5. Goldhirsch A, Winer EP, Coates AS, Gelber RD, Piccart-Gebhart M, Thurlimann B, Senn HJ (2013) Personalizing the treatment of women with early breast cancer: highlights of the St Gallen international expert consensus on the primary therapy of early breast cancer 2013. Ann Oncol 24:2206-2223. https://doi.org/10.1093/ annonc/mdt303

6. Parker JS, Mullins M, Cheang MC, Leung S, Voduc D, Vickery T, Davies S, Fauron C, He X, Hu Z, Quackenbush JF, Stijleman IJ, Palazzo J, Marron JS, Nobel AB, Mardis E, Nielsen TO, Ellis MJ, Perou CM, Bernard PS (2009) Supervised risk predictor of breast 
cancer based on intrinsic subtypes. J Clin Oncol 27:1160-1167. https://doi.org/10.1200/jco.2008.18.1370

7. Sorlie T, Perou CM, Tibshirani R, Aas T, Geisler S, Johnsen H, Hastie T, Eisen MB, van de Rijn M, Jeffrey SS, Thorsen T, Quist H, Matese JC, Brown PO, Botstein D, Lonning PE, Borresen-Dale AL (2001) Gene expression patterns of breast carcinomas distinguish tumor subclasses with clinical implications. Proc Natl Acad Sci USA 98:10869-10874. https://doi.org/10.1073/pnas.19136 7098

8. Perou CM, Sorlie T, Eisen MB, van de Rijn M, Jeffrey SS, Rees CA, Pollack JR, Ross DT, Johnsen H, Akslen LA, Fluge O, Pergamenschikov A, Williams C, Zhu SX, Lonning PE, BorresenDale AL, Brown PO, Botstein D (2000) Molecular portraits of human breast tumours. Nature 406:747-752. https://doi. org/10.1038/35021093

9. Guiu S, Michiels S, Andre F, Cortes J, Denkert C, Di Leo A, Hennessy BT, Sorlie T, Sotiriou C, Turner N, Van de Vijver M, Viale G, Loi S, Reis-Filho JS (2012) Molecular subclasses of breast cancer: how do we define them? The IMPAKT 2012 Working Group Statement. Ann Oncol 23:2997-3006. https://doi.org/10.1093/ annonc/mds586

10. Sorlie T, Tibshirani R, Parker J, Hastie T, Marron JS, Nobel A, Deng S, Johnsen H, Pesich R, Geisler S, Demeter J, Perou CM, Lonning PE, Brown PO, Borresen-Dale AL, Botstein D (2003) Repeated observation of breast tumor subtypes in independent gene expression data sets. Proc Natl Acad Sci USA 100:84188423. https://doi.org/10.1073/pnas.0932692100

11. Criscitiello C, Disalvatore D, De Laurentiis M, Gelao L, Fumagalli L, Locatelli M, Bagnardi V, Rotmensz N, Esposito A, Minchella I, De Placido S, Santangelo M, Viale G, Goldhirsch A, Curigliano G (2014) High Ki-67 score is indicative of a greater benefit from adjuvant chemotherapy when added to endocrine therapy in luminal B HER2 negative and node-positive breast cancer. Breast (Edinburgh, Scotland) 23:69-75. https://doi.org/10.1016/j.breas t.2013.11.007

12. Laenkholm AV, Jensen MB, Eriksen JO, Rasmussen BB, Knoop AS, Buckingham W, Ferree S, Schaper C, Nielsen TO, Haffner T, Kibol T, Moller Talman ML, Bak Jylling AM, Tabor TP, Ejlertsen B (2018) PAM50 Risk of recurrence score predicts 10-year distant recurrence in a comprehensive danish cohort of postmenopausal women allocated to 5 Years of endocrine therapy for hormone receptor-positive early breast cancer. J Clin Oncol 36:735-740. https://doi.org/10.1200/jco.2017.74.6586

13. de Azambuja E, Holmes AP, Piccart-Gebhart M, Holmes E, Di Cosimo S, Swaby RF, Untch M, Jackisch C, Lang I, Smith I, Boyle F, Xu B, Barrios CH, Perez EA, Azim HA Jr, Kim SB, Kuemmel S, Huang CS, Vuylsteke P, Hsieh RK, Gorbunova V, Eniu A, Dreosti L, Tavartkiladze N, Gelber RD, Eidtmann H, Baselga J (2014) Lapatinib with trastuzumab for HER2-positive early breast cancer (NeoALTTO): survival outcomes of a randomised, open-label, multicentre, phase 3 trial and their association with pathological complete response. Lancet Oncol 15:1137-1146. https://doi. org/10.1016/s1470-2045(14)70320-1

14. Goldhirsch A, Wood WC, Coates AS, Gelber RD, Thurlimann B, Senn HJ (2011) Strategies for subtypes-dealing with the diversity of breast cancer: highlights of the St. Gallen international expert consensus on the primary therapy of early breast cancer 2011 . Ann Oncol 22:1736-1747. https://doi.org/10.1093/annonc/mdr30 4

15. Coates AS, Winer EP, Goldhirsch A, Gelber RD, Gnant M, Piccart-Gebhart M, Thürlimann B, Senn HJ, Panel M (2015) Tailoring therapies-improving the management of early breast cancer: St Gallen international expert consensus on the primary therapy of early breast cancer 2015. Ann Oncol 26:1533-1546. https://doi. org/10.1093/annonc/mdv221
16. Maisonneuve P, Disalvatore D, Rotmensz N, Curigliano G, Colleoni M, Dellapasqua S, Pruneri G, Mastropasqua MG, Luini A, Bassi F, Pagani G, Viale G, Goldhirsch A (2014) Proposed new clinicopathological surrogate definitions of luminal A and luminal B (HER2-negative) intrinsic breast cancer subtypes. Breast Cancer Res 16:R65. https://doi.org/10.1186/bcr3679

17. Curigliano G, Burstein HJ, Winer EP, Gnant M, Dubsky P, Loibl S, Colleoni M, Regan MM, Piccart-Gebhart M, Senn H-J, Thürlimann B, André F, Baselga J, Bergh J, Bonnefoi H, Brucker SY, Cardoso F, Carey L, Ciruelos E, Cuzick J, Denkert C, Di Leo A, Ejlertsen B, Francis P, Galimberti V, Garber J, Gulluoglu B, Goodwin P, Harbeck N, Hayes DF, Huang C-S, Huober J, Hussein K, Jassem J, Jiang Z, Karlsson P, Morrow M, Orecchia R, Osborne KC, Pagani O, Partridge AH, Pritchard K, Ro J, Rutgers EJT, Sedlmayer F, Semiglazov V, Shao Z, Smith I, Toi M, Tutt A, Viale G, Watanabe T, Whelan TJ, Xu B (2017) De-escalating and escalating treatments for early-stage breast cancer: the St. Gallen International Expert Consensus Conference on the Primary Therapy of Early Breast Cancer 2017. Ann Oncol 28:1700-1712. https://doi.org/10.1093/annonc/mdx308

18. Varga Z, Diebold J, Dommann-Scherrer C, Frick H, Kaup D, Noske A, Obermann E, Ohlschlegel C, Padberg B, Rakozy C, Sancho Oliver S, Schobinger-Clement S, Schreiber-Facklam H, Singer G, Tapia C, Wagner U, Mastropasqua MG, Viale G, Lehr HA (2012) How reliable is Ki-67 immunohistochemistry in grade 2 breast carcinomas? A QA study of the Swiss Working Group of breast- and gynecopathologists. PLoS ONE 7:e37379. https://doi. org/10.1371/journal.pone.0037379

19. Polley MY, Leung SC, McShane LM, Gao D, Hugh JC, Mastropasqua MG, Viale G, Zabaglo LA, Penault-Llorca F, Bartlett JM, Gown AM, Symmans WF, Piper T, Mehl E, Enos RA, Hayes DF, Dowsett M, Nielsen TO (2013) An international Ki67 reproducibility study. J Natl Cancer Inst 105:1897-1906. https://doi. org/10.1093/jnci/djt306

20. Dowsett M, Nielsen TO, A'Hern R, Bartlett J, Coombes RC, Cuzick J, Ellis M, Henry NL, Hugh JC, Lively T, McShane L, Paik S, Penault-Llorca F, Prudkin L, Regan M, Salter J, Sotiriou C, Smith IE, Viale G, Zujewski JA, Hayes DF, International Ki-67 in Breast Cancer Working G (2011) Assessment of Ki67 in breast cancer: recommendations from the International Ki67 in Breast Cancer Working Group. J Natl Cancer Inst 103:1656-1664. https://doi. org/10.1093/jnci/djr393

21. Polley MY, Leung SC, Gao D, Mastropasqua MG, Zabaglo LA, Bartlett JM, McShane LM, Enos RA, Badve SS, Bane AL, Borgquist S, Fineberg S, Lin MG, Gown AM, Grabau D, Gutierrez C, Hugh JC, Moriya T, Ohi Y, Osborne CK, Penault-Llorca FM, Piper T, Porter PL, Sakatani T, Salgado R, Starczynski J, Laenkholm AV, Viale G, Dowsett M, Hayes DF, Nielsen TO (2015) An international study to increase concordance in Ki67 scoring. Mod Pathol 28:778-786. https://doi.org/10.1038/modpa thol.2015.38

22. Regional Cancer Center (2020) National care program breast cancer. Regional cancer center Stockholm Gotland. https://kunsk apsbanken.cancercentrum.se/diagnoser/brostcancer/. Accessed 8 June 2020

23. Acs B, Pelekanou V, Bai Y, Martinez-Morilla S, Toki M, Leung SCY, Nielsen TO, Rimm DL (2019) Ki67 reproducibility using digital image analysis: an inter-platform and inter-operator study. Lab Invest 99:107-117. https://doi.org/10.1038/s4137 4-018-0123-7

24. Rimm DL, Leung SCY, McShane LM, Bai Y, Bane AL, Bartlett JMS, Bayani J, Chang MC, Dean M, Denkert C, Enwere EK, Galderisi C, Gholap A, Hugh JC, Jadhav A, Kornaga EN, Laurinavicius A, Levenson R, Lima J, Miller K, Pantanowitz L, Piper T, Ruan J, Srinivasan M, Virk S, Wu Y, Yang H, Hayes DF, Nielsen TO, Dowsett M (2019) An international multicenter 
study to evaluate reproducibility of automated scoring for assessment of Ki67 in breast cancer. Mod Pathol 32:59-69. https://doi. org/10.1038/s41379-018-0109-4

25. Koopman T, Buikema HJ, Hollema H, de Bock GH, van der Vegt B (2018) Digital image analysis of Ki67 proliferation index in breast cancer using virtual dual staining on whole tissue sections: clinical validation and inter-platform agreement. Breast Cancer Res Treat 169:33-42. https://doi.org/10.1007/s10549-018-4669-2

26. Stalhammar G, Fuentes Martinez N, Lippert M, Tobin NP, Molholm I, Kis L, Rosin G, Rantalainen M, Pedersen L, Bergh J, Grunkin M, Hartman J (2016) Digital image analysis outperforms manual biomarker assessment in breast cancer. Mod Pathol 29:318-329. https://doi.org/10.1038/modpathol.2016.34

27. Stalhammar G, Robertson S, Wedlund L, Lippert M, Rantalainen M, Bergh J, Hartman J (2018) Digital image analysis of Ki67 in hot spots is superior to both manual Ki67 and mitotic counts in breast cancer. Histopathology 72:974-989. https://doi. org/10.1111/his. 13452

28. Senkus E, Kyriakides S, Ohno S, Penault-Llorca F, Poortmans P, Rutgers E, Zackrisson S, Cardoso F (2015) Primary breast cancer: ESMO clinical practice guidelines for diagnosis, treatment and follow-up. Ann Oncol 26(Suppl 5):v8-30. https://doi.org/10.1093/ annonc/mdv298

29. Rantalainen M, Klevebring D, Lindberg J, Ivansson E, Rosin G, Kis L, Celebioglu F, Fredriksson I, Czene K, Frisell J, Hartman J, Bergh J, Gronberg H (2016) Sequencing-based breast cancer diagnostics as an alternative to routine biomarkers. Sci Rep 6:38037. https://doi.org/10.1038/srep38037

30. Wang M, Klevebring D, Lindberg J, Czene K, Gronberg H, Rantalainen M (2016) Determining breast cancer histological grade from RNA-sequencing data. Breast Cancer Res 18:48. https://doi. org/10.1186/s13058-016-0710-8

31. McShane LM, Altman DG, Sauerbrei W, Taube SE, Gion M, Clark GM (2006) REporting recommendations for tumor MARKer prognostic studies (REMARK). Breast Cancer Res Treat 100:229-235. https://doi.org/10.1007/s10549-006-9242-8

32. Robertson S, Rönnlund C, de Boniface J, Hartman J (2019) Retesting of predictive biomarkers on surgical breast cancer specimens is clinically relevant. Breast Cancer Res Treat 174:795-805. https://doi.org/10.1007/s10549-018-05119-2

33. Bankhead P, Loughrey MB, Fernandez JA, Dombrowski Y, McArt DG, Dunne PD, McQuaid S, Gray RT, Murray LJ, Coleman HG, James JA, Salto-Tellez M, Hamilton PW (2017) QuPath: open source software for digital pathology image analysis. Sci Rep 7:16878. https://doi.org/10.1038/s41598-017-17204-5

34. Malpica N, de Solorzano CO, Vaquero JJ, Santos A, Vallcorba I, Garcia-Sagredo JM, del Pozo F (1997) Applying watershed algorithms to the segmentation of clustered nuclei. Cytometry 28:289-297. https://doi.org/10.1002/(sici)1097-0320(19970 801)28:4<289:aid-cyto3>3.0.co;2-7

35. Breiman L (2001) Random forests. Mach. Learn. 45:5-32

36. Kos Z, Dabbs DJ (2016) Biomarker assessment and molecular testing for prognostication in breast cancer. Histopathology 68:70-85. https://doi.org/10.1111/his.12795

37. Leung SCY, Nielsen TO, Zabaglo L, Arun I, Badve SS, Bane AL, Bartlett JMS, Borgquist S, Chang MC, Dodson A, Enos RA, Fineberg S, Focke CM, Gao D, Gown AM, Grabau D, Gutierrez C, Hugh JC, Kos Z, Laenkholm AV, Lin MG, Mastropasqua MG, Moriya T, Nofech-Mozes S, Osborne CK, Penault-Llorca FM, Piper T, Sakatani T, Salgado R, Starczynski J, Viale G, Hayes DF, McShane LM, Dowsett M (2016) Analytical validation of a standardized scoring protocol for Ki67: phase 3 of an international multicenter collaboration. NPJ Breast Cancer 2:16014. https://doi. org/10.1038/npjbcancer.2016.14

38. Leung SCY, Nielsen TO, Zabaglo LA, Arun I, Badve SS, Bane AL, Bartlett JMS, Borgquist S, Chang MC, Dodson A, Ehinger
A, Fineberg S, Focke CM, Gao D, Gown AM, Gutierrez C, Hugh JC, Kos Z, Laenkholm AV, Mastropasqua MG, Moriya T, NofechMozes S, Osborne CK, Penault-Llorca FM, Piper T, Sakatani T, Salgado R, Starczynski J, Sugie T, van der Vegt B, Viale G, Hayes DF, McShane LM, Dowsett M (2019) Analytical validation of a standardised scoring protocol for Ki67 immunohistochemistry on breast cancer excision whole sections: an international multicentre collaboration. Histopathology 75:225-235. https://doi. org/10.1111/his. 13880

39. Jang MH, Kim HJ, Chung YR, Lee Y, Park SY (2017) A comparison of Ki-67 counting methods in luminal breast cancer: the average method vs. the hot spot method. PLoS ONE 12:e172031. https://doi.org/10.1371/journal.pone.0172031

40. Cardoso F, Kyriakides S, Ohno S, Penault-Llorca F, Poortmans P, Rubio IT, Zackrisson S, Senkus E (2019) Early breast cancer: ESMO clinical practice guidelines for diagnosis, treatment and follow-up †. Ann Oncol 30:1194-1220. https://doi.org/10.1093/ annonc/mdz173

41. Burstein HJ, Curigliano G, Loibl S, Dubsky P, Gnant M, Poortmans P, Colleoni M, Denkert C, Piccart-Gebhart M, Regan M, Senn HJ, Winer EP, Thurlimann B (2019) Estimating the benefits of therapy for early-stage breast cancer: the St. Gallen international consensus guidelines for the primary therapy of early breast cancer 2019. Ann Oncol 30:1541-1557. https://doi.org/10.1093/ annonc/mdz235

42. Ditsch N, Untch M, Thill M, Müller V, Janni W, Albert US, Bauerfeind I, Blohmer J, Budach W, Dall P, Diel I, Fasching PA, Fehm T, Friedrich M, Gerber B, Hanf V, Harbeck N, Huober J, Jackisch C, Kolberg-Liedtke C, Kreipe HH, Krug D, Kühn T, Kümmel S, Loibl S, Lüftner D, Lux MP, Maass N, Möbus V, Müller-Schimpfle M, Mundhenke C, Nitz U, Rhiem K, Rody A, Schmidt M, Schneeweiss A, Schütz F, Sinn HP, Solbach C, Solomayer EF, Stickeler E, Thomssen C, Wenz F, Witzel I, Wöckel A (2019) AGO recommendations for the diagnosis and treatment of patients with early breast cancer: update 2019. Breast Care 14:224-245. https://doi.org/10.1159/000501000

43. Krop I, Ismaila N, Andre F, Bast RC, Barlow W, Collyar DE, Hammond ME, Kuderer NM, Liu MC, Mennel RG, Van Poznak C, Wolff AC, Stearns V (2017) Use of biomarkers to guide decisions on adjuvant systemic therapy for women with early-stage invasive breast cancer: american society of clinical oncology clinical practice guideline focused update. J Clin Oncol 35:2838-2847. https://doi.org/10.1200/jco.2017.74.0472

44. Stevanovic L, Choschzick M, Moskovszky L, Varga Z (2019) Variability of predictive markers (hormone receptors, Her2, Ki67) and intrinsic subtypes of breast cancer in four consecutive years 2015-2018. J Cancer Res Clin Oncol 145:2983-2994. https://doi. org/10.1007/s00432-019-03057-0

45. Danish Breast Cancer Group (2017) Pathology. Danish Breast Cancer Cooperative Group. https://dbcg.dk/vaerktoejer/retningsli njer-vejledninger. Accessed 8 June 2020

46. Vyberg M, Nielsen S (2016) Proficiency testing in immunohistochemistry-experiences from Nordic Immunohistochemical Quality Control (NordiQC). Virchows Arch 468:19-29. https:// doi.org/10.1007/s00428-015-1829-1

47. Saha M, Chakraborty C, Arun I, Ahmed R, Chatterjee S (2017) An advanced deep learning approach for Ki-67 stained hotspot detection and proliferation rate scoring for prognostic evaluation of breast cancer. Sci Rep 7:3213. https://doi.org/10.1038/s4159 8-017-03405-5

48. Sparano JA, Gray RJ, Makower DF, Pritchard KI, Albain KS, Hayes DF, Geyer CE Jr, Dees EC, Perez EA, Olson JA Jr, Zujewski J, Lively T, Badve SS, Saphner TJ, Wagner LI, Whelan TJ, Ellis MJ, Paik S, Wood WC, Ravdin P, Keane MM, Gomez Moreno HL, Reddy PS, Goggins TF, Mayer IA, Brufsky AM, Toppmeyer DL, Kaklamani VG, Atkins JN, Berenberg JL, Sledge 
GW (2015) Prospective validation of a 21-gene expression assay in breast cancer. N Engl J Med 373:2005-2014. https://doi. org/10.1056/NEJMoa1510764

49. Sparano JA, Gray RJ, Makower DF, Pritchard KI, Albain KS, Hayes DF, Geyer CE Jr, Dees EC, Goetz MP, Olson JA Jr, Lively T, Badve SS, Saphner TJ, Wagner LI, Whelan TJ, Ellis MJ, Paik S, Wood WC, Ravdin PM, Keane MM, Gomez Moreno HL, Reddy PS, Goggins TF, Mayer IA, Brufsky AM, Toppmeyer DL, Kaklamani VG, Berenberg JL, Abrams J, Sledge GW Jr (2018) Adjuvant chemotherapy guided by a 21-gene expression assay in breast cancer. N Engl J Med 379:111-121. https://doi.org/10.1056/ NEJMoa1804710

50. Cardoso F, van't Veer LJ, Bogaerts J, Slaets L, Viale G, Delaloge S, Pierga JY, Brain E, Causeret S, DeLorenzi M, Glas AM,
Golfinopoulos V, Goulioti T, Knox S, Matos E, Meulemans B, Neijenhuis PA, Nitz U, Passalacqua R, Ravdin P, Rubio IT, Saghatchian M, Smilde TJ, Sotiriou C, Stork L, Straehle C, Thomas G, Thompson AM, van der Hoeven JM, Vuylsteke P, Bernards R, Tryfonidis K, Rutgers E, Piccart M (2016) 70-gene signature as an aid to treatment decisions in early-stage breast cancer. N Engl J Med 375:717-729. https://doi.org/10.1056/NEJMo a1602253

Publisher's Note Springer Nature remains neutral with regard to jurisdictional claims in published maps and institutional affiliations. 